\title{
STRANGE CONCEPTUAL BEDFELLOWS: ASSESSING GROUNDED THEORY FOR EFFECTIVE VIRTUAL STUDENT TEAM PROJECT DELIVERY VIA KNOWLEDGE MANAGEMENT, QUALITATIVE RESEARCH AND MANAGEMENT THEORY
}

\author{
Michael F. Lohle, Ph.D., University of Bridgeport, mlohle@bridgeport.edu \\ Steven R. Terrell, Ph.D., Nova Southeastern University, terrell@nova.edu
}

\begin{abstract}
This case study tests the efficacy of a grounded theoretical model and related best practices developed to assist online instructors in facilitating virtual student team projects. The lived experience of two successful project teams comprised of seven students charged with delivering a term paper was analyzed to confirm the validity of the theoretical model. The findings exhibit commonality with previous findings in the knowledge management, qualitative research and management theory literature and reinforce and extend the findings of a previous case study focused on the lived experience of an unsuccessful project team.
\end{abstract}

Keywords: Knowledge Management, virtual teams, grounded theory, theoretical sampling, punctuated equilibrium, swift trust, project management

\section{INTRODUCTION}

This study assessed a theoretical model developed from an analysis of the lived experience of students during a fully online project management course that included a virtual team project where students delivered a term paper. Virtual projects and virtual teams cross the boundaries of organizations, cultures, time and geography and their collaboration is facilitated using information and communication technology (ICT) (Hislop, 2013; Meredith, Mantel and Shafer, 2015).

While the inclusion of this virtual student team project introduced challenges for the instructor, it was added to the course's design because online courses provide an excellent opportunity for students to experience what it is like to deliver projects on virtual teams. The researchers analyzed longitudinal data captured in the course's learning management system (LMS) and devised a grounded theory model and best practices to help online instructors facilitate virtual student team projects.

After publishing their theoretical model the researchers recommended conducting additional case studies using the same longitudinal data because the student feedback used to develop the model was captured during the course's first three weeks, coinciding with the completion of the student projects' initiation phase. While it was useful to base their theory on this data subset it did not provide a full picture so they next focused on the case study of an unsuccessful team.

This case study continues where the previous case study finished and leverages the same longitudinal data, this time focused on the lived experience of two virtual student project teams that achieved success. This study's research question focused on whether the lived experiences of two successful project teams supported Lohle and Terrell's theoretical model over the full project life cycle. It answered the research question by testing the model with the study's findings. The following sections explain this case study's methodology, describe the researchers' findings and conclusions and suggest opportunities for further research.

\section{RESEARCH METHODOLOGY}

Qualitative analysis was conducted to establish Lohle and Terrell's theoretical model using LMS data captured during an online project management course comprised of feedback from 34 students over three eight week semesters. Open 
and axial coding was conducted and the central phenomenon, or the phenomenon's central focus, was defined (Creswell, 2011; Glaser and Strauss, 1968). Table 1 displays the open code analysis supporting this theoretical model.

Table 1. Open coding analysis from Lohle and Terrell's grounded theory

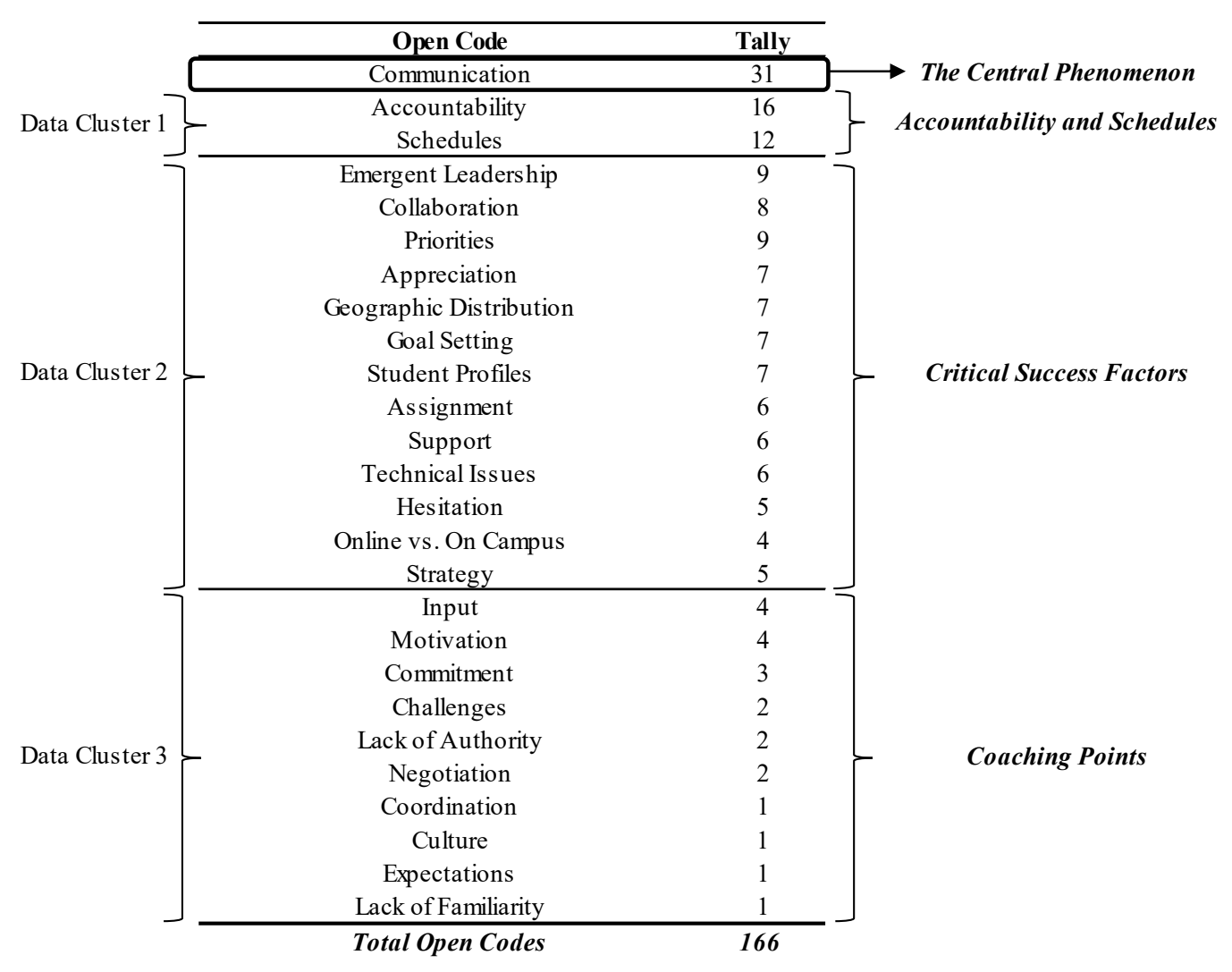

Figure 1 depicts Lohle and Terrell's grounded theoretical model:

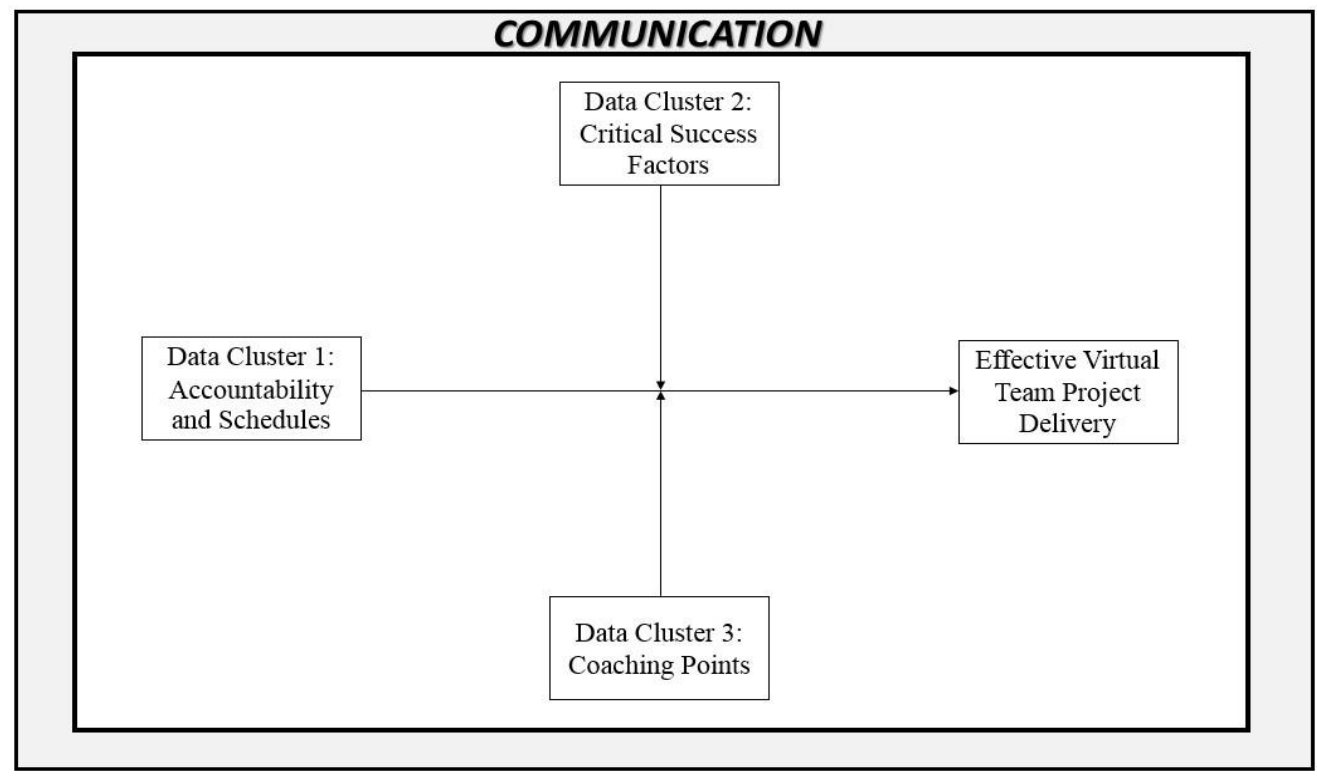

Figure 1. A Grounded Theoretical Model for Effective Student Project Delivery on Virtual Teams 


\section{Issues in Information Systems \\ Volume 18, Issue 1, pp. 180-190, 2017}

Student concerns about communication far exceeded the number of other open codes in Table 1; therefore effective communication was identified as the central phenomenon. It bounds the model and should infuse every aspect of virtual student team projects. Student concerns about accountability and scheduling also dominated the open code tallies, making it reasonable to conclude that developing project schedules and fostering accountability for delivering timely, quality results will have a positive influence on delivery effectiveness. Implementing some or all of the critical success factors and coaching points will also provide a positive impact.

Given the relationship between communication, accountability and scheduling, adding these three open codes to data clusters 1 and 2, comprising the critical success factors and coaching points, appears logical. It is therefore helpful to reconfirm that the large number of communication, accountability and scheduling open code occurrences, as well as students' emphasis on a sense of urgency and their concerns about these three codes, drove the researchers to consider them separately. Accordingly, data cluster 1, focusing on accountability and scheduling, is the theoretical model's dependent variable with critical success factors and coaching points serving as moderating variables.

\section{The Learning Management System as a Knowledge Repository}

Hislop's critical introduction to knowledge management discussed the codification of tangible, accessible explicit knowledge and tacit knowledge that is inseparable from its owner. He also discussed information and communication technologies (ICTs), confirming an organization's knowledge requirements should shape its technical approach. For instance, an organization whose core competency is customer service may emphasize the use of knowledge sharing via mentoring while another organization whose core competency is repeatable delivery might favor business process models and document management so knowledge can be shared with minimal human intervention.

These concepts resonate here. In this case study, the LMS used by a small university in the northeastern United States served as a knowledge repository that provided extensive explicit knowledge in the form of longitudinal data captured over several semesters. Student discussions, personal reflections, status reports and e-mails were anonymized and leveraged to glean insight into students' lived experience.

\section{Theoretical Sampling}

Charmaz (2006) confirmed theoretical sampling helps researchers understand the next steps in finalizing their initial theoretical models, further explaining previously defined constructs to ensure the theory fits the data. More purposeful than simply teasing themes from data, theoretical sampling provides an opportunity to achieve deeper insight. Charmaz' statement resonates, "As you engage in theoretical sampling your work gains clarity that transcends the immediate topic."

Eisenhardt (1989) stated theoretical sampling helps confirm whether researchers have achieved "good theory." Lohle and Terrell's previous case study focused on a "negative case" which Charmaz described as a situation that does not appear to support the model. While the findings from their negative case did not necessarily call the model into question, the researchers did confirm teams experiencing duress appear to emphasize different theoretical constructs depending upon their situation. This case study takes that analysis a step further, focusing on a positive case to examine the lived experience of two successful project teams.

Since Charmaz asserted theoretical sampling requires the acquisition of additional data, it is reasonable to question whether using a static "snapshot" of longitudinal data covering a discrete time period from this course's LMS is sufficient. The researchers concluded the LMS data is robust enough for three reasons. First, these studies emphasized different communication vehicles with some overlap during the course's first three weeks. Then, five weeks of additional data captured over three semesters was also available for review. Finally, while the initial grounded theory study assessed three weeks of LMS data for all teams across three semesters, this and the previous case study delved deeply into data specific for three project teams over the entire eight week semester. This assured the breadth covered in the initial grounded theory study was complimented by the depth covered in these case studies.

\section{Course Content}

This case study focused on a student team research project. Deliverables were assigned as follows:

- The first week students confirmed how they would communicate, collaborate and hold students accountable.

- The second week students provided a summary of their research topic.

- From the third to the seventh weeks students submitted weekly status reports. 
- Students submitted their final research papers at the end of the eighth week.

This case analysis covers data captured using these four communication vehicles:

- Weekly project status reports.

- Weekly student personal reflections.

- Summaries of e-mail escalation between the students and the instructor.

- Summaries of instructor video feedback about these e-mail escalations.

\section{Team Selection}

Two successful project teams were chosen for this case study. For the purposes of this analysis, these teams are named Team 1 and Team 2. Team 1 consisted of three students, referenced here as Student A, Student B and Student C. Team 2 consisted of four students, referenced here as Student D, Student E, Student F and Student G.

\section{FINDINGS}

Team 1 experienced the following between January 24 and March 6, 2016. January 24

Team 1 agreed to use Google Docs as their primary communication tool and established a standing weekly meeting. They also agreed to record meeting minutes and to use the LMS for daily communication, shared e-mail addresses and telephone numbers and confirmed if a team member could not finish their tasks on schedule their tasks would be "handed off to another team member for completion as required." The team also acknowledged Student A had planned his honeymoon later in the semester and offered to support him in his absence. Finally, they confirmed if a team member did not invest sufficient effort the others would confront that individual and exclude them from the team.

In his weekly personal reflection Student A confirmed one of Team 1's members had withdrawn from the course. He anticipated the team would come together despite this and mentioned, "I've already learned how important communication is among members of a group" in describing the confusion that had occurred when the remaining team members lost contact with the missing student. Student A also noted the additional challenge of working on a virtual team, "Working in groups always has its own sets of challenges and to amplify that, this group project will have no physical "face to face' interactions. All communication will be done electronically."

\section{January 30}

The team chose their research topic.

\section{February 7}

This week the team experienced a delay due to "uncertainties surrounding...initial topic selection." After Student B escalated concern about Team 1's research paper topic via e-mail to the instructor, the instructor worked with the team to refocus it. They agreed to a new topic described in their status report as "less ambiguous," acknowledged the need to "consider future decisions more carefully," and noted they had lost a week and were now behind schedule. They still asserted, "The risk is considered minimal."

In his weekly personal reflection Student B affirmed, "This past week was a little rocky for both myself and [my] team...the team, as you know, came upon some difficulty...in doing so however, I learned some valuable lessons." He concluded Team 1 lacked leadership during their recent confusion. Noting each team member had interpreted the instructor's feedback differently, compounding the confusion, he had stepped into a leadership role to facilitate, anticipated doing so regularly and asserted, "We have found our footing again and should be moving ahead much more smoothly."

Referring to the team's confusion in his video feedback to Student B, the instructor discussed Tuckman's (1965) phases of team engagement, "storming, forming, norming and performing," acknowledged Team 1 had come together 
in revising their research topic and in doing so appeared to have strengthened their teamwork. He hoped this was a harbinger of subsequent positive progress.

Student A concurred with Student B's assessment in his reflection, mentioning the previous week was "a learning week for my group and I...everyone has a strong opinion on [our] topic and how to complete our tasks from week to week." He mentioned Team 1 had published a document that allocated the work and provided a mechanism to monitor weekly progress and stated the team's topic change "may be a risk but we feel it's a better move going forward."

\section{February 14}

This week's status report confirmed Team 1 was back on schedule. They had finalized a new outline, started their paper's initial draft, agreed on a project work breakdown structure and "set lofty goals to get back on track."

In his personal reflection Student A confirmed considerable additional work was required to make up for "lost time" and said the team had agreed to hold each other accountable. He acknowledged setting stretch goals appeared to have galvanized them, "We have set the stage for weeks to come and if every week moving forward is like this week we could potentially finish ahead of schedule."

February 21

Team 1's status report confirmed they assigned sections of the paper and started drafting them, stating, "We feel as though we are ahead of schedule." This report also acknowledged Student A would be away on his honeymoon the following week and took it in stride, "We have planned for this and this risk is considered minimal."

In his personal reflection Student A acknowledged it was a busy week as he prepared to leave. He was thankful that Team 1 had arranged their task assignments so they could deliver ahead of schedule and affirmed, "We continue to work well together."

February 28

Despite missing the deadline for several sections of their paper Team 1 reported remaining on their overall schedule though "the original time horizon for these outputs proved to be more aggressive than we originally estimated."

\section{March 6}

This week's status report confirmed two sections of Team 1's research paper still remained, now delayed by two weeks. Once again, they admitted their original schedule had been more aggressive than anticipated and now intended to finish the remaining sections the following week.

As the research paper's delivery date approached Student A confirmed the team was on track to deliver with no issues.

\section{March 12}

The instructor awarded Team 1 a high score.

Team 2 experienced the following between April 3 and May 20, 2016.

April 3

Team 2 agreed to use Skype, text messaging and e-mail and confirmed three of the team's four students lived close to one other and could physically meet if necessary and conduct teleconferences with the remote student. They agreed to remain in contact throughout each week and drafted an action list, broke their work down into work packages and agreed to provide regular status updates to each other. 
April 10

The team chose their research topic.

In her personal reflection Student E confirmed Team 2's project was going well. She also reported needing to travel on business later during the semester, noted her team had finished their tasks ahead of schedule and stated, "We really have a nice group dynamic and support one another when needed."

Student G reported Team 2 was communicating daily. Gratified their remote communication was effective, she affirmed her teammates were responsive, "It is exciting to realize what an engaged team I am part of."

April 16

In her personal reflection Student $\mathrm{F}$ expressed gratitude for her teammates' support during an unexpected personal loss. She also noted Team 2 now agreed if e-mail was ineffective they would either text each other or use Skype and concluded, "I enjoy working with each of them."

April 17

Team 2 published a project timeline GANTT chart with their weekly status report. A project GANTT chart is a graphical timeline with bar charts depicting project milestones for visual reference (Meredith, Mantel and Shafer). Their status report stated they had conducted initial research and a draft of their paper's findings section was scheduled for the following week. Citing concerns with communication, Team 2 now agreed to meet twice weekly and reiterated if issues could not be rectified via text messaging they would meet via Skype.

In her personal reflection Student G reported, "It was a great week for my team as communication was really at an all-time high." She also confirmed the GANTT chart prepared team members for pending work. Observing her teammates' swift responses, she stated, "I am very happy with how the team has come together, and in just a short time grown to depend on and trust one another."

April 24

This week's GANTT chart depicted completed deliverables using a different color than that used for pending deliverables. Team 2 had delivered the first section of their research paper and were in the process of reviewing it and providing feedback. Drafts for several remaining sections were scheduled for simultaneous delivery the following week.

After publishing this status report the team realized they had scheduled too many simultaneous tasks so they escalated their concern to the instructor who provided video feedback suggesting ways to adjust their timeline. This challenge forced Team 2 to re-baseline their project schedule.

In her personal reflection Student E acknowledged Team 2 had struggled, “...but we did such a great job of communicating and coming together. Even when we had questions and things were not clear, we kept in constant communication. It was great!" She also thanked the instructor for recording video feedback and mentioned, "As always, there were no issues with our group activity. We communicate often and work well together, at least so far."

Student G reported "another great week for our team" while acknowledging Team 2 had to react quickly to deal with their challenge the previous week, "The team really pulled together and communicated clearly in order to update and correct our group assignment. This was a great success for the team, as we were able to act in the face of a crisis, and really work together to understand what went wrong, how we could update the assignment, and how to prevent this from happening again." 
May 1

This week's GANTT chart now depicted both Team 2's initial and revised project timelines. While two additional sections of the research paper were completed, the chart now displayed new bars that depicted the remaining rescheduled sections. Their status report confirmed, "The team unanimously decided that it would be best to postpone these sections until the drafts of the Introduction and Lessons Learned were completed...This change has been updated on the GANTT. The yellow blocks denote the new schedule." They also highlighted the risk this delay presented, "With the new schedule there is a risk with being back loaded with tasks. To mitigate these risks we will do a check in at the scheduled completion of each task to assure we stay on schedule during the last week so the last task can be completed." The report confirmed subsequent versions of their GANTT chart would depict the re-baselined project schedule.

In his personal reflection Student D discussed Team 2's recent project re-baselining and confirmed they had learned the importance of ensuring their project tasks were sequenced correctly, "Going through last week's exercise probably helped us to get to this conclusion a little faster instead of struggling through it and trying to force it to work." He reaffirmed the others' feedback that Team 2 had quickly adjusted and reengineered the project schedule.

May 8

This week's GANTT chart now depicted the revised project schedule while the status report confirmed Team 2 had completed three of the four sections of their research paper and the final section's delivery was on schedule with no risk.

In her personal reflection Student G remained confident but expressed concern about delivering the final report on time. She affirmed, "I believe we have left ourselves with enough time to do so, and this is not actually a risk, more of a challenge when working with a remote team and I am confident we will thrive."

May 12

Student E submitted her weekly personal reflection before leaving on her previously announced business trip. Confirming Team 2's work proceeded well, she said, "It was nice to see how understanding my teammates are regarding my circumstance." She was glad she had told them she had to travel in advance because her teammates had agreed to finalize their assignments a week early to accommodate.

May 15

Team 2's weekly status report confirmed their draft research paper was finished and they were reviewing and consolidating completed sections. It also confirmed they had addressed concerns about Student E's absence by completing their assignments before she departed.

In her personal reflection Student $\mathrm{G}$ applauded the fact that Team 2 had supported Student E's absence, "It's surprising how quickly we were able to come together and make decisions as a team. If not for this, it could have been a much more difficult process, and I doubt we would be as far along as we are now."

May 20

Team 2 received a near perfect grade. 


\section{DISCUSSION}

The experience of teams 1 and 2 exhibited several commonalities. Both teams:

- Established and adhered to an aggressive communication strategy including early notification when team members would not be available. Both teams also communicated honest, accurate project status and the content of their personal reflections aligned with their status reports. They did not communicate with the instructor outside the project's established communication mechanisms except when they encountered crises and required additional support.

- Published documents depicting their project work breakdown structures and schedules. Each used these documents to understand, plan, track and report status. In addition, Team 2 published a GANTT chart with each status report.

- Experienced initial confusion, came together to address crises, adjusted and moved forward. This supports the punctuated equilibrium model Gersick $(1988 ; 1989 ; 1991)$ described based on Niles and Gould's (1972) paleontological findings. Niles and Gould devised this model to refute the assertion that evolution occurs along a slow, seamless progression. Instead, they observed the fossil record indicates periods of stasis punctuated by dramatic "revolutions," followed by more stasis throughout the evolutionary lifecycle. Gersick observed this phenomenon also applies in business where project teams tend to proceed initially with relative stasis, experience challenges around midpoint and then either adjust, come together and succeed or fail. Here Team 1 chose a project that was too broad, started pursuing it and then retrenched and chose a different topic while Team 2 scheduled too many simultaneous deliverables and then re-baselined their schedule. After each crisis both teams came together and achieved success.

- Evolved from swift trust to benevolence. Jarvenpaa, Knoll and Leidner (1998) described the concept of "swift trust," a situation where team members come together on virtual teams but never meet so they tend to review and trust in the skills depicted in their teammates' professional profiles. These profiles set expectations that team members can trust each other to deliver on their commitments. As a result, virtual teams tend to devalue benevolence and emphasize delivery during their early stages so it is crucial to deliver early and often. Jarvenpaa, et. al. also observed several characteristics exhibited by high trust virtual teams that teams 1 and 2 both displayed: team members were proactive, focused on results, engaged in positive, supportive communication, rotated leadership, allocated assignments while remaining flexible, aggressively managed their time, provided substantial feedback, clarified tasks with their instructor and communicated frequently. Adopting these characteristics enabled teams 1 and 2 to successfully transition from swift trust to benevolence.

The grounding provided by this case study supports Lohle and Terrell's theoretical model:

\section{Central Phenomenon Analysis}

- Communication. The findings reinforce the researchers' conclusion that without communication their theoretical model could not exist. Constant, empathetic communication sustained both teams during crises and fostered trust and benevolence among team members.

\section{Independent Variable Analysis}

- Accountability. Both teams held each other accountable via the publication of work breakdown structures, proactive alerts about attendance, timeline adjustments to accommodate absences and supportive feedback.

- Scheduling. Both teams published schedules and Team 2 took the additional step of submitting a GANTT chart with their weekly status reports. 


\section{Moderating Variable Analysis}

- Teams 1 and 2 applied many of the open codes within the critical success factors and coaching points including managing geographic distribution, setting clear goals, employing emergent leadership, communicating appreciation and commitment, reckoning with challenges and engaging in active coordination and expectation setting.

\section{Dependent Variable Analysis}

- Since both teams received high scores the effective application of the theoretical model appears to have increased their probability of success.

\section{Instructor Engagement}

Lohle and Terrell's previous, negative case study reported two concerns about the high level of instructor engagement required to manage virtual team project delivery during online courses. In that case:

- The instructor was required to actively engage the team throughout the project.

- The team provided contradictory feedback in their status reports, personal reflections and e-mail.

In this "positive case," neither Team 1 nor Team 2 exhibited these traits. Instead, both teams emphasized communication via the project's established channels and only escalated during crises. Moreover, the content of their status reports, personal reflections and e-mail was not contradictory.

\section{CONCLUSIONS AND RECOMMENDATIONS FOR FUTURE RESEARCH}

This study's findings confirmed the lived experience of two successful virtual student project teams supported Lohle and Terrell's grounded theory. Both teams exhibited high trust in successfully navigating challenges at project midpoint, used the project's established communication vehicles and required minimal instructor support. These conclusions fostered additional observations and recommendations:

- Both Gersick and Jaarvenpaa, et. al. confirmed virtual student team members tend to engage instructors to clarify tasks, especially when faced with challenges. Considering the findings of both this and Lohle and Terrell's previous case study it appears reasonable to conclude when instructors facilitate virtual team projects they should anticipate varying levels of student escalation. It would be interesting to test more negative and "positive" cases to devise best practices to help instructors achieve a repeatable, manageable level of student engagement.

- Using case studies to conduct theoretical sampling with a static and broad dataset like the LMS data used here appears helpful in further grounding and testing theoretical construct validity. Additional case studies using this LMS data should be conducted.

- Recommending virtual teams publish and share project work breakdown structures and timelines appears to increase their effectiveness. Team 2's GANTT chart proved especially facilitative for both team and instructor. Testing whether requiring such documents also reduces the instance of low trust teams would provide additional insight.

- Though Gersick observed the punctuated equilibrium model applies on collocated projects in both academic and business settings, both this and Lohle and Terrell's previous case study prove it also applies on virtual teams. Therefore, when online instructors facilitate virtual student team projects they should anticipate these teams will 
encounter crises around midpoint and prepare for them. Testing to see if the timing and duration of such "midpoint crises" varies would also be instructive.

- Since teams 1 and 2 both exhibited characteristics of high trust virtual teams it would also be interesting to evaluate whether unsuccessful teams exhibit the characteristics of low trust virtual teams.

- Considering this case's findings as well as those from Lohle and Terrell's previous case study, it appears helpful for instructors to discuss the characteristics of low and high trust teams, the concept of swift trust and the importance of moving virtual teams to benevolence when initiating virtual student team projects. It would also be interesting to compare how effectively or ineffectively virtual student teams deliver when this information is shared or withheld.

- In their initial grounded theory study Lohle and Terrell recommended when online instructors facilitate virtual student team projects they should explain the importance of establishing effective communication, accountability and scheduling. They also suggested student teams employ as many of the critical success factors and coaching points as possible to increase the probability of effective project delivery. This case study supports those best practices and the researchers recommend conducting additional case studies to further test these conclusions.

- These recommendations focus on virtual student team projects conducted during online courses. It would be interesting to further the research with collocated student teams. In addition, Lohle and Terrell's theoretical model should be tested in business settings to assess its applicability beyond academia.

\section{REFERENCES}

Charmaz, K. (2006). Constructing grounded theory: A practical guide through qualitative analysis. Thousand Oaks, CA: Sage Publications, Inc.

Creswell, J. W. (2007). Qualitative inquiry and research design: Choosing among five approaches (2nd ed.). Thousand Oaks, CA: Sage Publications, Inc.

Eldrege, N., \& Gould, S. (n.d.). Punctuated equilibria: An alternative to phyletic gradualism. In Schopf, Thomas J. M. (ed.), Models in Paleobiology (pp. 82-115). San Francisco: Freeman, Cooper and Company.

Eisenhardt, K. (1989). Building theories from case study research. The Academy of Management Review, 14(4), 532-550. Retrieved from http://www.jstor.org/stable/258557

Gersick, C. J. G. (1988). Time and transition in work teams: Toward a new model of group development. Academy of Management Journal, 31(1), 9-41.

Gersick, C. J. G. (1989). Predictable transitions in task groups. The Academy of Management Journal, 32(2), 274309.

Gersick, C. J. G. (1991). Revolutionary change theories: A multilevel exploration of the punctuated equilibrium paradigm. The Academy of Management Review, 16(1), 10-36.

Glaser, B. G., \& Strauss, A. L. (1967). The discovery of grounded theory: Strategies for qualitative research. Chicago, IL: Aldine Publishing Company.

Hislop, D. (2013). Knowledge management in organizations: A critical introduction. Oxford. Oxford University Press.

Jarvenpaa, S. L., Knoll, K., \& Leidner, D. E. (1998). Is anybody out there? Antecedents of trust in global virtual teams. Journal of Management Information Systems, 14(4), 29-64. 


\section{Issues in Information Systems \\ Volume 18, Issue 1, pp. 180-190, 2017}

Lohle M. \& Terrell, S. (2016). Knowledge management using student feedback: A study of online students' lived experience on virtual teams. Issues in Information Systems, 17(4), $260-265$.

Lohle M. \& Terrell, S. (2017). The endurance test: A virtual project team's lived experience in an online course. Online Journal of Knowledge Management, 5(1), 1 - 13.

Meredith, J. R., Mantel, S. R., \& Shafer, S. M. (2015). Project management: A managerial approach. Hoboken, NJ: John Wiley \& Sons, Inc.

Tuckman, B. (1965). Developmental sequence in small groups. Psychological Bulletin, 63, 384-399. 